\title{
Entre o espiritual e o temporal: o probabilismo e a teologia moral dos séculos XVI ao XVIII
}

Rafael Bosch Batista ${ }^{1}$

\section{RESUMO}

O presente artigo é o resultado dos estudos realizados por meio da pesquisa "Daniel Concina e a história do probabilismo (séculos XVI-XVIII)", realizada com o apoio de uma bolsa de iniciação científica financiada pela FAPESP durante os anos de 2010 e 2011. Essa pesquisa relaciona-se com o grupo de estudos "Direitos e Justiça nas Américas", coordenado por Rafael Ruiz, do Núcleo de Estudos Ibéricos da Escola de Filosofia Letras e Ciências Humanas da Universidade Federal de São Paulo.

Estuda-se, nesse grupo, como as leis dos séculos XVI ao XVIII eram relativizadas de modo a se criarem espaços de ambuiguidade entre estas e seu cumprimento. Nesse sentido, este artigo busca demonstrar como a Teologia Moral se relacionava com as questões jurídicas e políticas, e busca ressaltar, também, a importância desta como um objeto para a compreensão destas questões no que diz respeito à Península Ibérica.

PALAVRAS-CHAVES: Teologia moral, probabilismo, Companhia de Jesus, história ibérica moderna, América colonial e espaços de ambiguidade no cumprimento de leis.

\section{Introdução}

\footnotetext{
${ }^{1}$ Estudante da graduação do curso de História da Universidade Federal de São Paulo, no sétimo termo do período vespertino.
} 


\section{Cadernos de Clio, Curitiba, n. ${ }^{\circ}$ 3, 2012}

Parece inconteste à historiografia que o século XVI é um ponto chave no que diz respeito à Teologia Moral. Alguns autores sustentam a tese de que há uma grande crise no seio da Igreja, em que os princípios fundantes do catolicismo foram abalados por uma nova e relaxada forma de se pensar a moral cristã (Cf. PINCKAERS, 2000.), já outros sustentam que é um período de revolução com resultados positivos, pois esta nova forma possibilitou a dinamização da consciência humana e a complexificação das discussões em torno do comportamento humano (Cf. DELUMEAU, 1991.). No entanto e por ora, o que cabe ressaltar é que esse fenômeno está diretamente relacionado à popularização do casuísmo na região ibérica, ocorrida entre o século XV e XVI.

Mas, afinal, do que se trata a Teologia Moral e o Casuísmo? A Teologia Moral é uma área da teologia dedicada a estudar e pesquisar a conduta humana (Cf. PINCKAERS, 2000.). Já o casuísmo católico foi uma corrente da Teologia Moral que buscava analisar a conduta humana por meio de casos concretos e singulares ou, em outras palavras, caso a caso, buscando causas e soluções aos casos de consciência (BAROJA, 1985: 535-538). Alguns fatores podem explicar a popularização dessa corrente na Península Ibérica.

Em primeiro lugar, temos, de modo geral, uma complexificação do Catolicismo. Tomando a guisa de exemplo a 
noção de pecado, esta se tornava cada vez mais densa, pois, além de se discutir se este era venial ou mortal, distinção que parecia cada vez mais líquida do que exata, novas questões entravam em debate, como, por exemplo, sua natureza, a ocasião, a intenção no ato, a reincidência e etc. (DELUMEAU, 1991: 73-96).

Ademais, mostra-se de suma importância levar em conta as particularidades da Península Ibérica. Trata-se de uma região completamente heterogênea no âmbito cultural e religioso, onde as três grandes religiões monoteístas viviam em contato constante, seja este pacífico ou conflituoso. Essa peculiaridade catalisava o surgimento de diversas questões de difícil - ou, em muitos casos, sem aparente - solução, de modo que a análise casuística figurava como um dos métodos mais empregados (Cf. SCHWARTZ, 2009.).

Não podemos nos olvidar também que a descoberta do Novo Mundo veio a agravar esse contexto. Como já foi demonstrado em diversas obras, discutia-se se as novas terras seriam o paraíso perdido, se os habitantes que ali viviam eram humanos, se possuíam almas, se viviam conforme a Lei Natural, se estavam sob o jugo de Cristo e, consequentemente, se podiam lograr a salvação eterna. Além disso, a instalação de missões de conversão no novo continente propiciou o surgimento de novas questões éticas que não possuíam solução nas sagradas escrituras, abrindo margem para uma gama de discussões (LEWIS, s.d. e 1998; SCHWARTZ, 2009; ZAVALA, 1971). 
Assim, por mais que a Teologia Moral tenha se consolidado como cátedra universitária e que - considerando isso como um fator também - o casuísmo tenha triunfado (Cf. DELGADO, 2004), diversas questões não possuíam solução, mesmo através do viés casuísta, o que tornava a dúvida - seja em relação a como se agir ou julgar - algo constante. Desse modo, uma das formas de se agir perante a dúvida - questão que, como pretendemos demonstrar, parece ter sido de grande importância foi o emprego do provável.

\section{O probabilismo}

Sob esse contexto, Bartolomé de Medina, teólogo dominicano professor da universidade da Salamanca, ao comentar a obra Prima Secundae de Tomás de Aquino em 1577, afirma que lhe parecia lícito, em caso de dúvida, optar por uma opinião provável em detrimento de outras mais prováveis (CONCINA, 1772: 9.). Os estudiosos do tema sustentam que seu comentário irrompeu de tal modo que a teologia moral passa a ser pensada em níveis de probabilidade, de modo que esta se viu dividida em diversos sistemas morais que defendiam maneiras distintas de como se proceder em relação à dúvida e ao provável (Cf. BAROJA, 1985, PINCKAERS, 2000; e DELUMEAU, 1991.).

Cabe ressaltar que Medina não pretendia criar um sistema a partir de seu comentário, este se construiu a partir de diversos 
teólogos que teorizaram sobre sua interpretação com o intuito de se criar seus princípios norteadores. Portanto, Medina não pode ser considerado o criador do probabilismo, e sim apenas aquele que possibilitou seu surgimento (Cf. CONCINA, 1772). Desse modo, teólogo Gabriel Vazquez foi, segundo Daniel Concina, o primeiro jesuíta a analisar a questão do provável e defender a menor probabilidade. Após este, "la autoridad gravíssima de Mercado, Lopes, Bañez, Valencia, Azorio, Enriquez, Salas, Suarez, y Sanchez fue un estimulo eficacíssimo á otros Thelogos posteriores para declararse por el partido probabilístico" (CONCINA, 1772: pp. 1025), possibilitando, desse modo, a constituição e a popularização do probabilismo.

A princípio, pode soar estranho pensar em probabilismo e/ou opiniões prováveis, pois, invariavelmente, o termo "probabilidade" remete à probabilidade matemática. No entanto, cabe notar que tal associação não é de todo errada, pois em tratados matemáticos do período é possível de se encontrar aplicações sociais da probabilidade matemática com a justificativa de que a reflexão humana carece de certeza absoluta e, por tal, esta deve operar a partir da probabilidade. Assim, em um desses tratados, afirma-se que a opinião de um douto acerca do assunto de sua alçada é quatro vezes mais provável do que a de um mero conhecedor deste assunto (Cf. MARTIN PLIEGO; DEL CERRO, 2000.). 
Esse tipo de relação foi amplamente utilizado no âmbito teológico, de modo que as opiniões defendidas pelos grandes padres da Igreja ou aquelas baseadas nas sagradas escrituras eram tidas como muito prováveis. Opiniões defendidas por teólogos comuns também poderiam ser entendidas como prováveis e quão maior fosse o número de defensores dessas opiniões, mais provável ela seria. O cerne do debate se dá em relação ao nível de probabilidade necessário para se agir na ausência da certeza. O princípio básico do sistema probabilista defendia que - como já foi demonstrado - face à incerteza, era lícito optar por uma opinião provável em detrimento de outras mais prováveis. Durante fins do século XVI a meados do XVII o probabilismo triunfou, tanto na literatura quanto na prática do confessionário e nas cátedras universitárias (LLAMOSAS, 2011: 285.). Durante esse período, estabeleceram-se princípios que, em certa medida, orientavam os teólogos de orientação probabilista.

Em primeiro lugar, quem age provavelmente age prudentemente e quem age prudentemente não peca. $\mathrm{O}$ conceito de prudência, sob a lógica ibérica do período, é enormemente influenciado por Aristóteles, o qual é retomado por Tomás de Aquino, que após o Concílio de Trento é tido como o grande guia teológico para assuntos morais (SCHWARTZ, 2009: 33.). Desse modo, Aquino afirma, baseando-se explicitamente em Aristóteles, que a prudência é "uma virtude da razão prática e não da razão especulativa" (AQUINO, 2005: 5). Ademais, 
Cadernos de Clio, Curitiba, n. ${ }^{\circ}$ 3, 2012

É próprio da prudência não só a consideração racional, mas também a aplicação à ação, que é o fim da razão prática. Só pode haver aplicação adequada se houve conhecimento dos dois polos: o que se aplica e ao qual se aplica. Ora, as ações versam sobre realidades singulares. E assim é necessário que a prudência conheça os princípios universais da razão e também que conheça esses singulares sobre os quais versam as ações. (AQUINO, 2005: 5-6)

Portanto, esta versa sobre a ação em relação aos casos singulares. Associada a essa noção, Aquino retoma, também, a equidade aristotélica ao afirmar que "Os atos humanos - sobre os quais incidem as leis - são singulares e contingentes e, portanto, podem se dar com uma infinita variedade de modos. Daí que não seja possível estabelecer uma lei que não falhe em algum caso concreto" (AQUINO, 2005: 64.). E, assim, em determinados casos a lei pode ir contra a equidade da justiça, contra o bem comum, que é justamente o que a lei visa:

Nesses casos e em casos semelhantes, é mau seguir o que está estabelecido pela lei; e, pelo contrário, é bom passar por cima da lei e seguir o que pede o espírito da justiça e a utilidade comum. E é isso que faz a epiquéia, que entre nós se chama equidade. Fica assim evidente que a epiquéia é virtude. (AQUINO, 2005: 64-65)

Como Giovani Levi demonstrou, devido às fortes raízes católicas, a equidade, tanto na Península Ibérica como na Itália, foi um elemento central no sistema normativo, que, ao contrapor a fortemente arreigada inflexibilidade da justiça divina à 
especificidade humana, prescreveu ao juiz o dever de aplicar a lei conformando a razão à teologia (LEVI, 2009: 65-66). Tal característica remonta ao princípio probabilista de lex dubia non est lex. Os probabilistas, de forma geral, sustentavam que se uma lei, seja esta humana ou divina, fosse posta em dúvida por especialistas e surgisse razões prováveis em ambas as partes essa deixaria de ser obrigatória, de modo que se deva dar prioridade à liberdade de consciência em casos duvidosos. (Cf. CONCINA, 1772.)

Por fim, outro princípio norteador do probabilismo é o de que se em caso de dúvida uma sentença igualmente ou menos provável for escolhida em face da mais provável esta poderá se revelar falsa posteriormente, caso isto aconteça, a ação não será considerada como pecaminosa, pois se configurará como ignorância invencível e, portanto, não é culpável.

De maneira geral, esses princípios estruturam o probabilismo como um sistema moral que buscava conduzir a conduta das pessoas em meio às incertezas de sua realidade. No entanto, desde o seu surgimento, o probabilismo foi alvo de diversas críticas que, por assim dizer, moldaram outros sistemas morais. Entre estes sistemas, aquele que se posicionou como mais clara oposição ao probabilismo foi o probabiliorismo.

O probabiliorismo defende que, em caso de dúvida, devese sempre optar pela mais provável das opiniões. Daniel Concina, dominicano italiano e um dos maiores expoentes do 
probabiliorismo, escreveu em meados do XVIII Historia de probabilismo y rigorismo, , na qual constrói uma história dos diversos sistemas morais que estavam em meio da polêmica e dá maior atenção ao probabilismo, o qual é vítima de duras críticas. Nela sustentava que o probabilismo corrompia a moral cristã por meio de concessões que buscam facilitar a vida terrena, pois, por meio da menor probabilidade e dos princípios probabilistas, suavizava-se demais a Lei Evangélica. Cabe notar, no entanto, que no período da publicação dessa obra, o probabilismo já vivia sua decadência, mas, ainda assim, essa e outras obras de Concina foram amplamente utilizadas para se refutar as teses probabilistas (DELGADO, 2004: 246).

Concina sustenta que o conceito de probabilidade deve ser entendido como sinônimo de verossimilhança, de modo que quão mais provável fosse uma opinião mais verossímil ela seria, ou, em outras palavras, mais próxima da verdade (Cf. CONCINA, 1772). A partir dessa relação de sinonímia, o autor se baseia em Agostinho de Hipona ao afirmar que a lei de Deus é a verdade e Deus é a verdade (AGOSTINHO, 1997: 101), de modo que, segundo ele, aquele que opta por uma opinião menos provável em detrimento de outra mais provável está se afastando de Deus e, consequentemente, da salvação eterna.

Para além dessa argumentação, Concina define alguns pontos que sustentam o probabiliorismo. Tem-se, em primeiro 


\section{Cadernos de Clio, Curitiba, n. ${ }^{\circ}$ 3, 2012}

lugar, que o homem pode pecar tanto violando a lei como contradizendo sua consciência, de modo que se este seguir a opinião falsa de um teólogo estará pecando contra a lei mesmo que não peque contra sua própria consciência. Em segundo lugar, o autor afirma que mesmo entre diversas opiniões prováveis haverá apenas e obrigatoriamente uma opinião verdadeira. Por fim, Concina considera como culpado o homem que opera com uma opinião que esteja em estado de dúvida em relação a ser pecado ou não. Desse modo, pode-se notar que esses princípios se constituem como clara oposição ao probabilismo, buscando eliminar a liberdade de consciência por meio da busca de opiniões certas ou mais seguras.

\section{Debates morais}

No entanto, como se deram esses debates? Concina dedica um capítulo exclusivamente à questão do jejum no período da quaresma. Segundo ele, a doutrina de São Basílio era a mais aceita, a qual determinava a obrigatoriedade do jejum, contudo a excetuava em casos de enfermidade grave. No entanto, diversos probabilistas buscavam relativizar a questão de modo a torná-la mais branda. Estes, segundo Concina, defendiam que em várias situações o descumprimento do jejum não se configurava como pecado. Como, por exemplo, a fim de se evitar futuras enfermidades, em caso de fraqueza, ou, até mesmo, fome excessiva e "calores estomacais". (CONCINA, 1772: 106-117). 
Almeida, em um dos poucos artigos em língua portuguesa sobre o tema, demonstra que outro ponto muito discutido entre teólogos era o da concepção e da vida sexual. Diversos autores de orientação probabilista buscavam abrandar as rigorosas normas que regravam tais questões com a justificativa de que a natureza humana é fraca ou por conta da "extrema fragilidade do nosso barro". (ALMEIDA, 1996: 13). Desse modo, atentando-se à questão do incesto, para o ato ser configurado como tal seria necessário que "a semente do homem entre no membro natural da mulher" (NAVARRO in ALMEIDA, 1996: 13.), assim, qualquer ato sodomítico em que não houvesse contato do sémen com o órgão sexual feminino era tido como lícito. Tal posição permite concluir, como a autora afirma, que os temerosos de pecarem por incesto se viam encorajados a praticar relações de sodomia (ALMEIDA, 1996: 13).

No que diz respeito ao aborto, a questão parece um pouco mais polêmica, tendo-se em conta que este era tido como homicídio. Em alguns manuais de confessores - obras de teólogos em que se dava de maneira mais acentuada os debates aqui tratados defendia-se a tese de que o aborto de uma criatura sem alma racional seria um "homicídio imperfeito", o que justificava o ato em algumas situações, como a de perigo à mãe. No entanto, não havia um consenso sobre a aquisição da alma racional, "os fetos de menino já a teriam aos quarenta dias, e os de menina aos noventa, 
segundo a opinião de Aristóteles, enquanto Avicena dava um prazo de trinta dias para os meninos, e Alberto Magno, de vinte e cinco dias." (ALMEIDA, 1996: 15.), tornando, desse modo, a questão mais polêmica ainda.

De maneira mais abrangente e não menos polêmica, Schwartz demonstra que na Península Ibérica - graças a já discutida peculiaridade da região - tanto teólogos como homens comuns acreditavam que era possível de se lograr a salvação eterna das almas - o que era tida como uma das questões mais importantes no período - através das três grandes religiões monoteístas, pois estas estavam sustentadas em leis boas e sérias. (Cf. SCHWARTZ, 2009). Tal crença era uma clara oposição a um dos maiores dogmas da Igreja Católica, o do que a salvação só é possível através da Lei de Cristo.

No entanto, o debate probabilista não se limitava apenas ao âmbito espiritual, a distinção entre este e o temporal no período aqui abordado se mostrava demasiadamente tênue, principalmente no que diz respeito ao mundo ibérico, onde a linha divisória nunca foi claramente divida, o que tornava conflitos entre bispos e os poderes locais uma realidade constante (ELLIOT, 2004: 297.). Ademais, em diversos guias teológicos do período, encontram-se instruções de como um juiz deve se portar diante uma infinidade de casos, o que possibilita a discussão do probabilismo em uma esfera judicial. 
Cadernos de Clio, Curitiba, n. ${ }^{\circ}$ 3, 2012

\section{Entre o espiritual e o temporal}

Nesse sentido, Concina menciona que autores probabilistas defendiam a ideia de que o súdito não estava obrigado a seguir a opinião de seu superior, mesmo que essa seja tida como a mais provável das opiniões em questão (CONCINA, 1772: 154.), especialmente através do teólogo Escobar que defende a tese de "que el Pueblo no peca en no recibir, aun sin causa alguna, la ley promulgada pelo Principe" (CONCINA, 1772: 93). Assim, à guisa de exemplo, o autor afirma que a questão do pagamento de impostos ao soberano tendia ao caos, pois

si siendo probable, que el tributo es justo, y también que no lo es, puedo como exactor de él cobrarlo hoy, y mañana, y aun hoy, como mercader dexarlo de pagar? Y resuelve, que puede hacerse lícitamente esta variación, según que cada uno quiera. (CONCINA, 1772: 94.)

Delumeau, por sua vez, lista diversas proposições que influem no âmbito jurídico e que foram defendidas por teólogos probabilistas. Estes defendiam opiniões tidas como escandalosas, como, por exemplo, a de que "quando as partes contrárias têm a seu favor opiniões igualmente prováveis, o juiz pode aceitar dinheiro para se pronunciar por uma de preferência à outra" ou de que "se um consulente quer que se lhe responda segundo a opinião mais favorável, peca-se não o fazendo" (DELUMEAU, 1991: 111). De forma semelhante, Almeida, ao estudar as obras de confessores, 


\section{Cadernos de Clio, Curitiba, n. ${ }^{\circ}$ 3, 2012}

atenta que, na ótica destes, os juízes poderiam receber presentes como reconhecimento da justiça feita ou como meio de engajá-los a ter um cuidado particular com o caso em questão e resolvê-lo com presteza (ALMEIDA, 1996: 10).

É possível encontrar em alguns manuais de confissão de orientação probabilista até mesmo justificativa para homicídios. Alguns teólogos sustentavam que matar - seja de forma traiçoeira ou não - alguém em um duelo para defender a própria honra e prosperidade não era tido como pecado. (ALMEIDA, 1996: 9-10). Nesse sentido, alguns teólogos, principalmente a partir de Juan de Mariana, justificavam, por meio dos princípios probabilistas, o tiranicídio. Ou seja, se o soberano fosse tirano de modo a não obrar em prol da república ou da moral cristã, seu homicídio seria justificado e não tido como pecado (LLAMOSAS, 2011: 287.).

Aparentemente, uma das questões mais perturbadoras para parcela da sociedade residia na proposição mais óbvia que um teólogo de orientação probabilista pode sustentar: a de que "um juiz possa julgar conforme uma opinião inclusive menos provável" (LLAMOSAS, 2011, p. 287.). Pode-se afirmar isso, pois, como Concina observou, "no hay cosa, mas facil á un súbdito, especialmente impuesto en el Probabilismo, que el formar opinion probable, que favorezca su libertad" (CONCINA, 1772: 94.), principalmente se levarmos em conta que a opinião de que o conceito de probabilidade era relativo, afinal a opinião de qualquer 
especialista era tida como provável e que caso houvesse o conflito de duas opiniões contrárias acerca de uma mesma lei esta deixaria de ser obrigatória.

No entanto, no que concerne ao cumprimento ou descumprimento de leis, uma questão que parecia ser de suma relevância para a lógica probabilista diz respeito à existência de algum costume ou tradição em relação à promulgação desta. Diego de Avendaño, tido como primeiro e maior expoente do probabilismo latino-americano (BALLÓN, 2011: 28), discute, em sua Thesarus Indicus - publicada em 1668 -, a proibição régia da venda de folhas de coca no Peru. Avendaño sustenta que o consumo das folhas de coca no Peru se dá para uso medicinal, ademais, faz parte das tradições locais, por tal, a proibição da venda destas traria mais problemas do que soluções à república, assim, posiciona-se contrário à lei régia (PAREDES, 2007: 39-40). De maneira semelhante, Pablo Layman, primeiro autor a introduzir o probabilismo na região da Alemanha (CONCINA, 1772: 12-17.), sustentava que, os paulistas não deveriam ser excomungados por se utilizarem de trabalho indígena, pois isto já estava enraizado em seus costumes. Desse modo, o autor, embasando-se nas tradições locais, absolve-os de sua excomungação e legitima o emprego do trabalho indígena (Cf. RUIZ, 2008.).

Ademais, retomando a obra de Avendaño, ao tratar dos costumes, este se aprofunda em outro aspecto central da lógica 
probabilista, o papel da consciência individual. Para o autor, em alguns casos o indivíduo tem a liberdade de consciência para julgar se o cumprimento ou não da lei é válido. Um exemplo dessa situação é o trabalho forçado de indígenas em oficinas têxteis do Peru, o qual é proibido por Cédulas Reais, mas Avendaño sustenta que cabe à consciência individual julgar o cumprimento ou não de tais cédulas, pois, por maior que seja o dano do trabalho para os indígenas, ele se mostra de grande importância para o bem da república (PAREDES, 2007: 39-41).

Tais preceitos probabilistas, seja no âmbito temporal ou espiritual, produziram uma intensa campanha de combate ao dito sistema moral. De modo que a partir do século XVII os termos "casuísmo", "probabilismo" e derivados destes vieram a ter uma conotação pejorativa, pois foram usados para assinalar aqueles que aderiam ao laxismo moral (LLAMOSAS, 2011: 282). O laxismo era entendido como uma forma de se lidar com a moral cristã, em que a frouxidão e a condescendência reinavam. Desse modo, diversas condenações e proibições se seguiram a proposições de cunho probabilista.

Embora o probabilismo tenha surgido e se popularizado nos reinos ibéricos, a escalada anti-probabilista teve início na França. Cabe ressaltar que, segundo Concina, em meados do século XVII, o probabilismo teria se internacionalizado, de modo a lograr seu auge. No entanto, seu auge teria sido breve, pois logo em 1656 
párocos romanos e parisienses apresentam ao clero francês um grande catálogo de proposições tidas como escandalosas, as quais teriam aterrorizado todos os bispos presentes (CONCINA, 1772: 13-18). Após isso, tem-se uma onda de publicações de cunho antiprobabilista que culminam em uma série de condenações papais. Em 1665, Alexandre VII condenou 29 proposições e no ano seguinte mais 17 foram condenadas. Já em 1679, o então papa Inocêncio XI condenou mais 65 proposições probabilistas. Por fim, Alexandre VIII, em 1690, condena mais 51 proposições atribuídas ao probabilismo.

Entretanto, o debate entre probabilistas e anti-probabilistas parece ter gerado maior repercussão no âmbito das ordens religiosas. Embora, como foi mencionado, o dominicano Bartolomé de Medina tenha sido um dos grandes responsáveis pelo surgimento de uma doutrina probabilista, foram os jesuítas que acabaram sendo associados a este, de modo a serem tidos como os maiores defensores do sistema moral. Isso teria se dado em parte pela adoção do probabilismo por Francisco Suárez - autoridade seguida em todos os colégios e cátedras jesuíticas - e, por outro lado, essa associação teria se dado com o intuito de desacreditar a ordem jesuítica em tempos de perseguição e dissolução (LLAMOSAS, 2011: 285).

Desse modo, se estabeleceu uma relação de sinonímia entre os termos "casuísta", "probabilista" e "laxista", e pode-se dizer, 
também, que o termo “jesuíta” fazia parte dessa relação. A título de curiosidade, é interessante notar como o estabelecimento dessa relação logrou êxito e se mostrou inconteste até muito recentemente. Em fins do século XIX, em seu Os irmãos Karamázov, Dostoiévski constrói um interessante diálogo entre Fiódor Pavlóvitch - grande devasso e dado aos exageros -, Smierdiákov - sempre descrito como uma pessoa carrancuda, malagradecida e de má-índole e que, até o presente momento, não havia tido uma única fala -, e algumas outras personagens. Estas discutiam sobre as barbaridades das guerras e, ao tratarem de um caso em particular, quando Smierdiákov sustenta que

[...] uma vez que caí prisioneiro de verdugos da raça cristã e eles exigem que eu amaldiçoe o nome de Deus e renegue meu santo batismo, estou plenamente autorizado a fazê-lo pela própria razão, pois nisso não há nenhum pecado. (DOSTOIÉVSKI, 2009: 189).

Justifica essa proposição afirmando que

[...] Porque é só eu dizer aos verdugos: "Não, eu não sou cristão e amaldiçoo o meu verdadeiro Deus", que imediatamente eu serei anatemizado pelo supremo tribunal divino e totalmente excomungado pela santa Igreja como se fosse um pagão, [...] Portanto, se já não sou cristão, não posso tampouco renegar Cristo, porque neste caso não terei o que renegar. Quem vai cobrar do ímpio tártaro, Grigori Vassílievitch [tratase de seu pai], até mesmo nos céus, por ele não ter nascido cristão, e quem há de castigá-lo por isso, considerando que não se tiram dois couros de um só boi? E, ademais, se o próprio Deus-todo-poderoso vier a cobra algo desse tártaro, quando este morrer, 
Cadernos de Clio, Curitiba, n. ${ }^{\circ}$ 3, 2012

então suponho que venha a ser através de algum castiguinho à toa (uma vez que não é possível deixar totalmente de castigá-lo), por julgar que este não tem culpa de ter nascido ímpio de pais ímpios. (DOSTOIÉVSKI, 2009: 189-190)

Smierdiákov, ao analisar um caso bem específico, sustenta em seu discurso que, de certo modo e em outras palavras, a Lei Natural possibilita a salvação eterna das almas - por mais que haja um "castiguinho à toa" - daqueles que não estão sob o jugo da Lei de Cristo. Este argumento foi amplamente utilizado pelos probabilistas, principalmente os jesuítas em continente americano. No entanto, o mais interessante é a recepção desse discurso.

Grigori [pai do orador] estava boquiaberto e fitava o orador de olhos esbugalhados, [...] parou com ar de quem acabara de dar uma testada na parede. Fiódor Pávlovitch esvaziou o cálice e desatou uma risada esganiçada.

[...] Sim, senhor, seu casuísta. Ele aprendeu isso em algum lugar com jesuítas, Ivan [filho de Pávlovitch presente na discussão]. Tu, hem, seu jesuíta fedorento, quem foi que te ensinou isso? Só que tu estás dizendo lorotas, casuísta, lorotas, lorotas, lorotas. Não chores, Grigori [...].

- Lorotas, ma-mal-dito - chiou Grigori. [itálicos nossos] (DOSTOIÉVSKI, 2009: 191-192.)

Como é possível notar, o discurso foi recebido com terror e ojeriza, e, como buscamos realçar, estabeleceu-se - quase dois séculos após os debates casuístas - uma relação direta entre a Companhia de Jesus e o casuísmo, relação esta carregada de um claro tom pejorativo. 
Essa associação não era de todo falsa, afinal, os jesuítas, em grande medida, adotaram o probabilismo. Para se compreender isso, tem-se que levar em consideração que estes foram um dos maiores responsáveis pela educação e pelo proselitismo no Novo Mundo desde que os europeus chegaram nele. (BARNADAS, 2004: 529-530). Se o contexto europeu era o de incertezas em relação a como se proceder, o contexto americano tendia a ser mais incerto, pois se tratava de uma realidade completamente distinta e nunca antes vivida. Assim, parece natural que os jesuítas adotassem uma doutrina que pudesse compatibilizar a nova realidade à ortodoxia católica. Tal adoção pode ser comprovada através do estudo feito por Manuel Braga, citado por José Carlos Ballón. Braga faz um levantamento dos acervos das bibliotecas jesuíticas no Peru e constata uma grande quantidade de probabilistas nestas (Cf. BALLÓN, 2011.). Além disso, é interessante ressaltar que diversas universidades de orientação jesuíta no Novo Mundo se baseavam em autores probabilistas, o que é bem representativo. (DELGADO, 2004: 246.)

Essa adoção, como já foi mencionado, foi motivo de grandes debates com um viés nitidamente anti-jesuítico. Em 1656, os dominicanos foram os primeiros a proibirem o ensino de proposições probabilistas. Por tal, vangloriavam-se pela primazia no combate ao probabilismo e por terem, segundo Concina - que era dominicano -, influenciado nas condenações papais. (Cf. 
CONCINA, 1772.). No entanto, é interessante recordar que, como já foi demonstrado, Medina, era da ordem dominicana. O embate entre dominicanos e jesuítas também ocorreu no novo mundo, principalmente no âmbito das cátedras universitárias - cujas de orientação dominicana se baseavam no próprio Concina -, mas não obteve muita expressão graças ao predomínio jesuítico na educação americana.

Entretanto, o debate mais acentuado teve seu berço na França. Como um dos primeiros críticos pode-se citar Renée Descartes, que estudou em colégio jesuíta, e que, de maneira sutil, posiciona-se contrário à Companhia de Jesus ao afirmar em seu Discurso do Método, publicado em 1637, que aqueles que baseiam em meras probabilidades - o que era um recurso comum, segundo transparece - "são espíritos fracos e vacilantes" (DESCARTES, 1983: 42-43). Por isso, busca construir método sólido para bem conduzir a razão e se lograr certezas.

De maneira mais violenta se deu o debate entre jansenistas e jesuítas, este ocorreu por diversas questões, mas a maior expressão do debate no que diz respeito ao probabilismo se deu em 1657, quando Blaise Pascal se posiciona terminantemente contrário à Companhia de Jesus e do dito sistema moral em suas Provinciais. Empregando uma feroz crítica em tom satírico e defendendo o jansenismo, este sustentou que todo laxismo moral era fruto do probabilismo e que os jesuítas eram os grandes responsáveis pela 


\section{Cadernos de Clio, Curitiba, n. ${ }^{\circ}$ 3, 2012}

propagação deste (DELUMEAU, 1991: 97). Para Delumeau, a publicação das epístolas de Pascal é um grande marco no que diz respeito à decadência do probabilismo (DELUMEAU, 1991: 110). Cabe ressaltar, no entanto, que, apesar do sucesso da publicação, esta era motivo de crítica, tanto no meio intelectual probabilista como anti-probabilista. Isso se dava devido à defesa do jansenismo, ordem religiosa tida como rigorista, termo o qual deve ser entendido como o extremo oposto do laxismo. De modo que se este era condescendente demais com as ações humanas, o rigorismo, por sua vez, cobrava de uma massa imensa de fiéis o comportamento moral de uma pequena elite (DELUMEAU, 1991: 66).

Embora tenha sido alvo de críticas, as Provinciais e as proibições papais tiveram como consequência material a expulsão dos jesuítas. A Companhia de Jesus já se destacava negativamente por sua forma missionária que se baseava nas reduções, as quais eram tidas como uma sociedade alternativa em relação à dos colonos (BARNADAS, 2004: 544-545). Associado a isso, tem-se o fato de que os princípios probabilistas possibilitaram o estabelecimento uma margem de ambiguidade e negociação no que diz respeito às ordens da Coroa, de modo que "as leis inoportunas, embora olhadas com deferência devido à fonte que emanavam, não eram obedecidas, enquanto a própria autoridade era filtrada, mediada e dispersada", de modo que se dissolviam as certezas de Madrid através de sua ambiguidade, "onde "observar, mas não 
obedecer" era um artifício aceito e legítimo para desatender às vontades de uma coroa supostamente bem-informada." (ELLIOT, 2004: 299.).

Ademais, graças a uma complexa operação de propaganda, vinculou-se ao probabilismo e aos jesuítas a justificativa do regicídio que, como já foi demonstrado, alguns jesuítas aprovavam e ensinavam. Associado a isso, tem-se o contexto de mudança dinástica na Espanha, em que a nova dinastia, de influência francesa, buscou centralizar o poder e torna-lo mais eficaz (ORTIZ, 1999: 331-367). Assim, em pouco tempo a Companhia de Jesus é expulsa e dissolvida. Tal fato logo repercutiu na educação americana, em que as grades curriculares de influência jesuítica e, portanto, de orientação probabilista logo foram substituídas por doutrinas tidas como mais seguras. (DELGADO, 2004: 249-250).

Nesse sentido, em agosto de 1769, foi emitido um Tomo Regio que ordenava a imediata convocação de concílios eclesiásticos por toda a América espanhola. Entre outros assuntos, estes deviam se dedicar a

Exterminar las doctrinas relajadas y nevas sustituyéndolas por las antiguas de la Iglesia y de infundir en los vassalos, como antídoto contra el regicidio, amor y respecto a los superiores, haciêndoles ver que éstas eran obligaciones religiosas y no sólo civiles y naturales (MACERA, 1963: 95) 


\section{Cadernos de Clio, Curitiba, n. ${ }^{\circ}$ 3, 2012}

Tal contexto político tornou praticamente impossível a defesa do probabilismo, de modo que diversos teólogos que haviam publicado obras em defesa do probabilismo buscaram se retratar reescrevendo suas antigas obras ou publicando novas afirmando que estavam enganados em relação ao probabilismo. (LLAMOSAS, 2011: 292.)

Se no âmbito político e jurídico o probabilismo foi derrotado, por assim dizer, devido à dissolução da Companhia de Jesus e por conta das reformas advindas do câmbio dinástico espanhol, no âmbito teológico se deu graças ao advento do equiprobabilismo. Este sistema moral, criado por Afonso de Ligório em meados do XVIII, defendia que em caso de dúvida a pessoa deveria sempre estar atenta à honestidade da ação e só poderia optar por uma opinião provável quando escolhida entre outras tantas igualmente prováveis. (LLAMOSAS, 2011: 285). Segundo Delumeau, Ligório convidou o homem a assumir a responsabilidade ética e o risco de suas ações, mas, em contrapartida, o confortava e o desculpabilizava "quando tomava uma decisão com toda a boa-fé e cercado de garantias sérias" (DELUMEAU, 1991: 130.).

\section{Conclusão}

Sendo assim, no que resultou a polêmica em torno do probabilismo? Delumeau sustenta que este modelou uma moral mais bem adaptada aos problemas do período, pregou respeito à 
consciência, preconizando, desse modo, a defesa da liberdade individual (DELUMEAU, 1991: 108). Já Almeida sustenta que a história do probabilismo está completamente vinculada à ascensão da burguesia ilustrada, de maneira que em um âmbito privado, a burguesia fora contaminada pelo laxismo em nome do igualitarismo e da liberdade, desde que não prejudicasse a outrem (ALMEIDA, 1996: 17.), enquanto que em um âmbito público, esta fora contaminada pelo rigorismo em nome do combate à decadente aristocracia, pois a burguesia necessitava da concretude da lei para defender seus interesses econômicos. Sendo assim, podemos afirmar que o fenômeno do probabilismo e das discussões em torno deste configuram um período de transição entre um direito baseado essencialmente nos costumes e na livre interpretação para outro direito baseado na normatização e na mera aplicação das leis. Um período em que as relações entre o espiritual e o temporal foram de sobremaneira tensas, líquidas e, em meio a isso, sofreram mudanças que até hoje nos afetam.

Almeida, contemporizando ainda mais a discussão, defende a ideia de que na sociedade brasileira contemporânea existe apenas uma tênue linha que distingue o favor da corrupção, de modo que esta última só é entendida como tal quando envolve grandes somas de dinheiro. Tal construção, associada ao sentimento de permissividade e condescendência em relação à corrupção, está 
relacionada, em alguma medida com a influência jesuítica na educação no período colonial (ALMEIDA, 1996: 2).

À guisa de conclusão, o objetivo desse artigo é demonstrar que o estudo da teologia moral é de grande importância para compreendermos as relações jurídicas e políticas da idade moderna ibérica. Paolo Prodi defende que o ideal de justiça ocidental é anterior às codificações iluministas. Este advém do ethos (entendido como algo derivado dos costumes, tradições e éticas) e, por tal, o autor admite que o costume e a moral podem exercer um poder coercitivo sobre as pessoas, além da lei em si. (PRODI, 2005: 4-10). De forma semelhante, Llamosas afirma que para a historiografía latinoamericana não é mais necessário grandes justificações ou explicações para relacionar questões da teologia moral à história jurídica. (LLAMOSAS, 2011: 281.). No entanto e infelizmente, a tradição historiográfica brasileira ainda dá pouca atenção à questão, de modo que o já mencionado artigo de Almeida é um dos poucos que aborda a temática. Assim, termos como "consciência", "prudência", "probabilidade" entre outros acabam sendo associados apenas à história das religiões e da filosofia.

\section{Obras Consultadas}

AGOSTINHO. Confissões. São Paulo: Paulus, 1997. 
ALMEIDA, A. M. A casuística, o probabilismo e os manuais de confessores. In: VII Encontro Regional da ANPUH, 1996, Rio de Janeiro.

AQUINO, Tomás de. A prudência: a virtude da decisão certa. São Paulo: Martins Fontes, 2005.

ARISTÓTELES, Ética a Nicômaco - tradução, notas e textos adicionais de Edson Bini. Bauru, SP: Edipro, 2009.

BALLÓN, José Carlos, La complicada historia del pensamiento filosófico peruano: siglos XVII y XVIII. Lima: Ediciones del Vicerrectorado Académico de la UNMSM, 2011.

BARNADAS, Josep M. "A Igreja católica na América espanhola colonial”. In: BETHELL, Leslie (Org.). História da América Latina. América Latina Colonial (Vol. I) São Paulo: Edusp; Brasília: Fundação Alexandre Gusmão, 2004.

CONCINA, Daniel. Historia Del Probabilismo y Rigorismo: dissertaciones theologicas, morales, y criticas, en que se explican, $y$ defienden de las sutilezas de los modernos probabilistas los principios fundamentales de la Theologia Christiana. Madri: Oficina de la viuda de Manuel Fernandez, 1772. 
DELGADO, José Romero. "Iglesia, Estado y Sociedad en la educación colonial de la América Hispana durante el siglo XVIII”. Historia de la educación. Salamanca: Universidad de Salamanca, 2004, pp. 235-257.

DELUMEAU, Jean. A confissão e o perdão: as dificuldades na confissão católica nos séculos XIII a XVIII. São Paulo: Companhia das Letras, 1991.

DESCARTES, René. Discurso do método. São Paulo: Abril Cultural, 1983.

DOSTOIÉVSKI, Fiódor. Os irmãos Karamázov. São Paulo: Editora 34, 2008.

ELLIOT, J.H. "A Espanha e a América Latina nos séculos XVI e XVII". In: BETHELL, Leslie (Org.). Op cit.

HANKE, Lewis. Aristóteles e os índios americanos. Trad.: Maria Lúcia Galvão Carneiro. São Paulo: Livraria Martins Editora, s.d. . La lucha por justicia en la conquista de América. Madrid: Ediciones Istmo, 1988.

LEVI, Giovanni. "Reciprocidade Mediterrânea". In: OLIVEIRA, Mônica Ribeiro de et al (Org.) Exercícios de micro-história. Rio de Janeiro: Editora FGV, 2009.

LLAMOSAS, Esteban F. "Probabilismo, probabiliorismo y rigorismo: la teología moral en la enseñaza universitária y en la práxis judicial de la Córdoba tardocolonial". Cuadernos de 
Instituto Antonio de Nebrija. Córdoba: CONICET, 2011, pp. 281294.

MACERA, Pablo. "Probabilismo en el Perú durante el siglo XVIII", in Nueva crónica. Universidad Nacional Mayor de San Marcos. 1963.

PAREDES, Víctor Hugo. El lugar de Probabilismo en las ideas políticas del Perú. Lima: Solar, 2007.

MARTIN PLIEGO, F. Javier; DEL CERRO, Jesús. Aportaciones españolas a la génesis del concepto de probabilidad. Anais eletrônicos da XIV reunião de Economia Aplicada de Oviedo, 2000 .

PINCKAERS, Servais Théodore. Las fuentes de la moral cristiana. Su método, su contenido, su historia. Navarra: Ediciones Universidad de Navarra, 2000.

RUIZ, Rafael. Duas percepções da justiça nas Américas: Prudencialismo e Legalismo, VII Encontro Internacional da ANPHLAC Vitória, 2008.

SCHWARTZ, Stuart B. Cada um na sua lei: tolerância religiosa e salvação no mundo atlântico ibérico. São Paulo: Companhia das Letras, 2009.

ZAVALA, Silvio. Las instituciones jurídicas en la conquista de América. Mexico: Porrua, 1971. 